\title{
Rosella (Hibiscus sabdariffa) Flowers as Alternative Indicators of Blue and Red Litmus
}

\author{
SITI NURYANTI', DWI JULI PUSPITASARI ${ }^{2,1}$ and SUPRIADI ${ }^{1}$ \\ ${ }^{1}$ Faculty of Teacher Training and Education, Tadulako Universty, Palu 94118, Indonesia. \\ ${ }^{2}$ Faculty of Mathematics and Natural Sciences, Tadulako University, Palu 94118, Indonesia. \\ *Corresponding author E-mail: dwijulipuspitasari@gmail.com \\ http://dx.doi.org/10.13005/ojc/350163
}

Received: August 15, 2018; Accepted: January 31, 2019)

\begin{abstract}
The red and blue litmus indicators are an indispensable indicator for practials in secondary and higher education. The research has been done to make alternative indicator of litmus with rosella flower material. The procedures were rosella flowers were extracted, the filtrate was isolated by column chromatography, then the isolated compounds were analyzed using UV-Vis, FTIR, ${ }^{1} H$ HNR. The alternative indicator of red litmus is made by acid-activated paper, then the paper was macerated into the isolated compound solution. Meanwhile, The alternative indicators of blue litmus were made by similar to the red litmus, but the paper was activated by base. The comparative indicators were blue and red litmus. The isolated compound which acts as an indicator is a cyanidin-3-glycoside. The color change of rosella indicator paper is the same as the comparison indicator.
\end{abstract}

Keywords: Rosella (Hibiscus sabdariffa) flowers, Alternative indicator, Red litmus, Blue litmus.

\section{INTRODUCTION}

Laboratory experiments are demanded for the implementation of contextual based learning. The Studying process of chemistry need a proof in the laboratory because chemistry is the understanding of chemical reaction requires a practicum so in the chemistry course, practicum is an integral part with theory. Studying chemical change requires a verification between theory and real observation in the laboratory. For example, to distinguish an acid or base solution that is both colorless requires an indicator that can distinguish both types of solutions.
The acid-base indicators are materials that are practiced in high school of exact department. This indicator gives an indication of whether a compound is acidic or alkaline by giving a different color to a specific $\mathrm{pH}$ range. In acid-base titrations, the indicators used are from synthetic compounds. The use of synthetic indicators such as methyl orange, phenolphthalein and litmus become obstacles in the implementation of practicum in high school. The price is expensive because the materials and processes used are synthetic materials ${ }^{1}$. Therefore, there is a need to replace indicators of natural materials that are easy to obtain, cultivated, harmless, low cost and environmentally friendly.

This is an Open Access article licensed under a Creative Commons license: Attribution 4.0 International (CC- BY). Published by Oriental Scientific Publishing Company @ 2018 
Parts of plants such as stems, leaves, fruits, and flowers mostly contain flavonoid group pigments. The pigment is anthocyanin. Some research on the presence of anthocyanin such as in plants Euphorbia mili, Erythrina varigata and Nelumbo nucifera ${ }^{2}$ Rose (Rosa setigera), Allamanda (Allamanda cathartica), and Hibiscus (Hibiscus rosa-sinensis) flowers ${ }^{3}$ Wora wori flowers ${ }^{4}$. The anthocyanin pigment shows color changes in different $\mathrm{pH}$ ranges of red, blue and colorless ${ }^{5,6,7}$. Therefore, the colored parts of plant parts which contain anthocyanins can be used as a raw material for making acid-base indicators ${ }^{8}$.

The color change in acid and base solutions can be a guide in determining whether a material can be an acid-base indicator. From previous research on the isolation of anthocyanin from rosella flowers, the extract containing anthocyanin that will give red in acid and green in alkaline ${ }^{7}$. Based on these, it is very possible that rosella flowers can be used as the basic material of alternative indicator of red and blue litmus paper red and blue indicators are indispensable for practicum in high schools. The difficulty of obtaining such indicators leads to limited experimental acid-base experiments, this occurs in schools that are located in rural areas. The benefit of this research is that an indicator of rosella flowers can be used as an alternative of the red and blue litmus. The success of this research can increase the economis value of rosella, because the rosella was a hedge plant yard. The urgent benefit is to assist the ministry education overcome obstacles in implementation of laboratory practicum at high schools in rural areas. Long-term benefits will utilize the natural materials that is easily cultivated and environmental friendly, so that the need for acid-base indicators, especially red and blue litmus indicators for practical implementation on the chemical laboratory can be fulfilled.

\section{EXPERIMENTAL}

\section{Materials}

The Chemicals used in this study were: n-hexane, methanol, ethanol, ethyl acetate, TLC plates, silica gel 60, 70-230 mesh, $\mathrm{HCl} 1 \%$, $1 \% \mathrm{NaOH}, \mathrm{HCl} 1 \%$ in methanol ( $/ \mathrm{v}$ methanol), n-buthanol, distilled water, Whatman paper no. 1, red and blue litmus. Rosella flowers from Petobo Sigi Biromaru, Palu, Central Sulawesi, Indonesia.

\section{Instrumentation}

The Instrumens used in this study were: shaker for extraction (IKA® KS 130 basic), rotary evaporator (Buchii R-124), electric bath, dryers, Buchner funnel, analytical balance (METLER AT 200), FT-IR (Shimadzu Prestge- 21), TLC scanner (Camac3), UV-Vis (array Miltonroy 3000), $500 \mathrm{MHz}$ $1 \mathrm{H}-\mathrm{NMR} 125 \mathrm{MHz}$ (JEOL JNM ECA 500), micro pipettes (SOLOREK Switzerland) and Column chromatography (length $60 \mathrm{~cm}$, diameter $2 \mathrm{~cm}$ ).

\section{Procedure}

Extraction of rosella flowers

Exactly $500 \mathrm{~g}$ fresh colored rosella flowers was weighed, cut into small pieces. They were put in a dark colored bottle, after that they were extracted by using solvent that have different polarity. The maceration was done according to the procedure of ${ }^{7}$ activated carbon was washed by demineralized water in the shaker for $30 \mathrm{~min}$ then filtered and washed again using boiling water for 15 min to remove salt on from its the surface of activated carbon. After that, activated carbon filtered and was dried at $105^{\circ} \mathrm{C}$ for 3 hours. $20 \mathrm{~g}$ of activated carbon were reactivated in $100 \mathrm{~mL} \mathrm{HCl}$ $5 \%$ for $5 \mathrm{~h}$ at room temperature. The activated carbon was separated and then washed by aqua demineralized until the $\mathrm{pH}$ of solution was neutral $(\mathrm{pH}=7)$. The activated carbon then redried at $80^{\circ} \mathrm{C}$ for 48 hours.

\section{Isolation of Antosianidin from rosella flowers} Isolation of rosella flower extract began with thin layer chromatography(TLC). The procedure and solvent were done as procedure of ${ }^{7}$ furthermore, anthocyanidins was separated by column chromatography. Structure of anthocyanidins was identified by UV-Vis, FT-IR and ${ }^{1} \mathrm{H}-\mathrm{NMR}$.

\section{Making paper indicators as an alternative to litmus}

Before papers were tested with acid and base solutions, papers were activated by maceration using acid to adsorb anthocyanin. The procedure was done as procedure of ${ }^{4}$.

\section{The trials indicators as an alternative to litmus}

The dry blue and red Indicators of rosella flower were dipped in a solution of $\mathrm{HCl} 1 \%$, respectively. The color of blue indicator turned red but the red indicators were colorless. Using the same procedure, the dry blue and red indicator of rosella 
flowers were dipped in $1 \% \mathrm{NaOH}$. The color of red indicator turned blue but the blue indicator were colorless. The color changes is the same as litmus indicator.

\section{RESULTS AND DISCUSSION}

\section{Extraction of rosella flowers}

The red extract was obtained by extracting rosella flowers with methanol. After identification with $\mathrm{NH}_{3}$ vapor, the color turn to be blue which indicating that methanol solvent can extract anthocyanins. Based on the trial results, the extract of rosella flower in acid solution is red and blue in base solution.

The UV-Vis Spectrophotometer analysis showed that the maximum wavelength is at $\left(\lambda_{\text {max }}\right) 519$ $\mathrm{nm}$. Anthocyanin has an typical absorption $\lambda_{\max }$ in the region between $465-560 \mathrm{~nm}^{10}$. The analysis concludes that methanol extract contained anthocyanin. The analysis UV-Vis Spectrophotometer of rosella flower extract is shown in Figure 1.

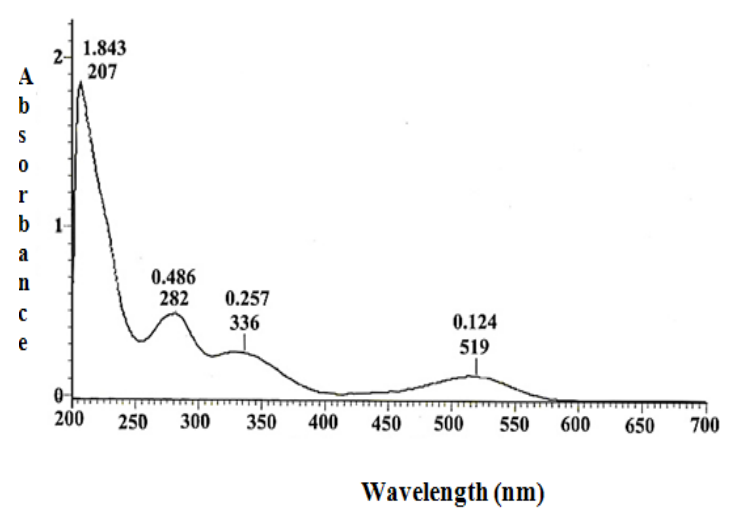

Fig. 1. UV-Vis specrum of rosella flower extract

Isolation of Antosianidin by column chromatography Based on result of column chromatography (CC) with eluent $n$-butanol : $\mathrm{HCl} 1 \%(4: 1,5), 2$ number spot (Rf 0.74$)$, the color of isolate with $\mathrm{NH}_{3}$ vapor was blue. Then the extract was separated and analyzed by UV- Vis resulting the absorption wavelength is at $537 \mathrm{~nm}$. It can be seen qualitatively that the isolation contained anthocyanin.

Based on the FTIR analysis, the absorption band at $1641.8 \mathrm{~cm}^{-1}$ showed the vibration range of conjugated $\mathrm{C}-\mathrm{O}$ bond with double bond of carboncarbon, which is likely refer to $\mathrm{C}-\mathrm{O}$ bond in purilium ring ( $\mathrm{C}$ ring). $\mathrm{C}=\mathrm{C}$ bonds come from the core of benzene that provides an absorption band at 1582.7 $\mathrm{cm}^{-1}$. The typical absorption bands of $\mathrm{C}=\mathrm{C}$ bonds likely overlap with the absorption of conjugated $\mathrm{C}-\mathrm{O}$, so that this absorption band is stretched. The absorption bands at $1449.5 \mathrm{~cm}^{-1}$ indicates that the nucleus of benzene contains substituents ${ }^{11}$.

According to ${ }^{1} \mathrm{H}$-NMR spectrometer analysis, it was obtained 7 types of protons with different chemical environments. Signal $(\delta 9.0442$ ppm, singlet, $1 \mathrm{H}$ ) describes proton in $\mathrm{C}-4$ atom on $C$ ring. Signal ( $\delta 8.2890$ to $8.2729 \mathrm{ppm}$, duplet, $\mathrm{J}=8.5 \mathrm{~Hz}, 1 \mathrm{H})$ and $(\delta 7.0245$ to $7.0174 \mathrm{ppm}$, duplet, $\mathrm{J}=8.5 \mathrm{~Hz} 1 \mathrm{H}$ ) show two aromatic protons of $B$ ring mutually at ortho position, ie C-5 'and C-6' proton, respectively. While signal ( $\delta 8.0515$ to $8.0497 \mathrm{ppm}$, duplet, $\mathrm{J}=1.25 \mathrm{~Hz}, 1 \mathrm{H}$ ) is derived from $\mathrm{C}-2$ ' proton experiencing meta coupling with C-6' proton. Furthermore, two singlet peaks of $(\delta 6.9030 \mathrm{ppm}$, singlet, $1 \mathrm{H})$ and $(\delta 6.5669 \mathrm{ppm}$, singlet, $1 \mathrm{H}$ ) represent two protons in $\mathrm{B}$ ring at $\mathrm{C}-8$ and $\mathrm{C}-6$. The presence of sugar group is presented by proton through the absorption of sugar group with integrate 7 protons in chemical shift from 3.9008 to $3.3114 \mathrm{ppm}$. A proton aromatic ring $(\mathrm{H}-6$ and $\mathrm{H}-8)$ gives the signal at $\delta=6.80$ and $7.10 \mathrm{ppm}$, while $\mathrm{B}$ proton aromatic ring appear at $\delta=7.50$ to $7.70 \mathrm{ppm}^{12}$. Based on anthocyanin identification with color reagent, $\mathrm{Pb}$ acetate, UV-Vis, FT-IR, and ${ }^{1} \mathrm{H}-\mathrm{NMR}$, it can be seen that rosella flower extract contain anthocyanin sianidin 3-glucoside (Figure 2).

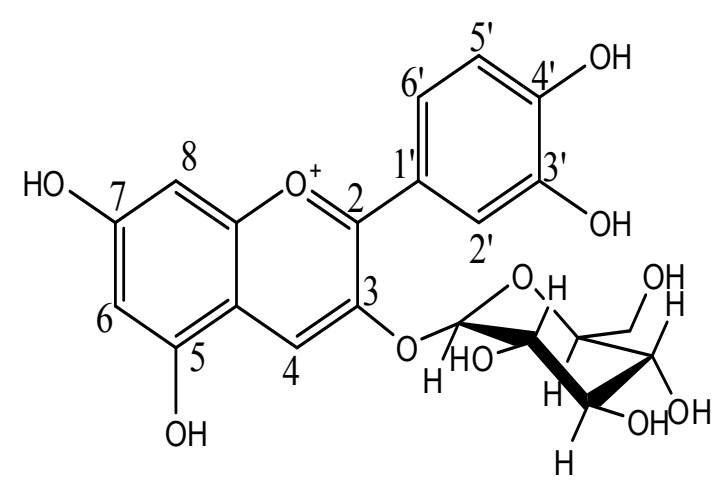

Fig. 2. Structure of sianidin-3-glucoside (13)

Making of indicator paper as alternative material of litmus substitute

Paper was activated with $\mathrm{HCl} 1 \%$ solution, then it macerated with sianidin-3-glycosides solution, the color turned red. This is caused by flavilium cation in the anthocyanin molecule is stable in acid solution ${ }^{14}$. 
The anthocyanin structure (I), red in acidic condition, when the $\mathrm{pH}$ is raised $(\mathrm{pH}<4)$ will form a colorless carbinol base (III) and subsequently toutomeri equilibrium forms khalkon (IV). At $\mathrm{pH}<6$, it undergoes a structural change to anhidrobase (II). The expansion of the delocal bond cause a stronger color change in intensity and produce a blue color. The anhydrobase provides absorption at the wavelength region $\left(\lambda_{\max }\right) 610 \mathrm{~nm}^{3}$. Changes in the structure of anthocyanin sianidine in various $\mathrm{pH}$ ranges are shown in Figure 3.
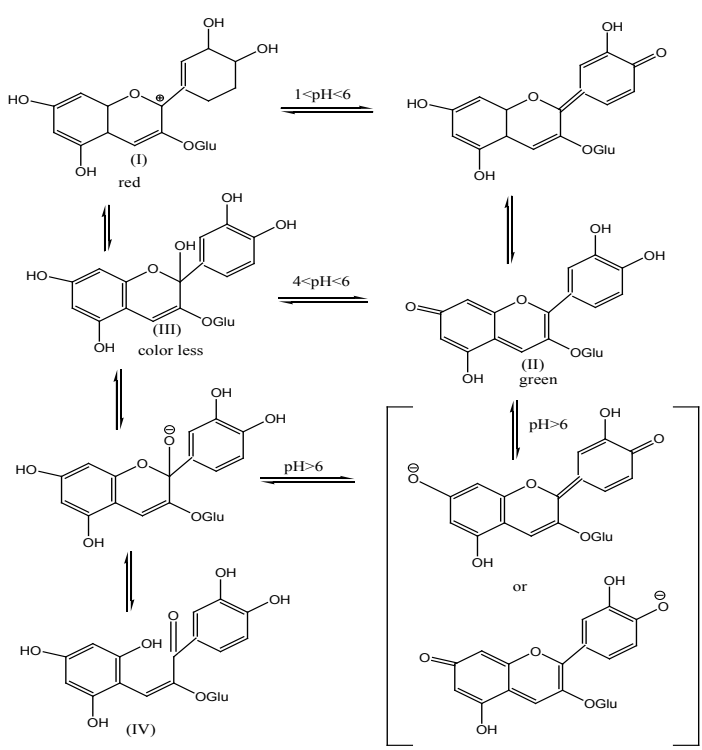

Fig. 3. Changes structure of anthocyanin sinanidin-3-glukosida in various ranges of $\mathrm{ph}(11)$

When the red indicator paper was immersed in alkaline solution, $\mathrm{H}$ at the $\mathrm{OH}$ group in the cation of flavilium formed a quinoid base. The expansion of the delocal bond resulted in a stronger color change in intensity and resulting in a blue color of quinoid or anhydrobase bases. The quinoid or anhydrobase base uptake $\lambda_{\max }$ region at $610 \mathrm{~nm}^{15}$. The results of the analysis with the UV-Vis spectrophotometer are shown in Figure 4.

Phenolphthalein indicator has a characteristic that is a compound that gives a color change to $\mathrm{pH}$ change of solution. Color changes can occur through balance process of molecular and ionic forms of indicator compounds. Process of ionic equilibrium change is followed by color change from colorless under acidic conditions to red under alkaline conditions. The shape of structural changes which follows change of color in Phenolphthalein compound as in Figure 5.

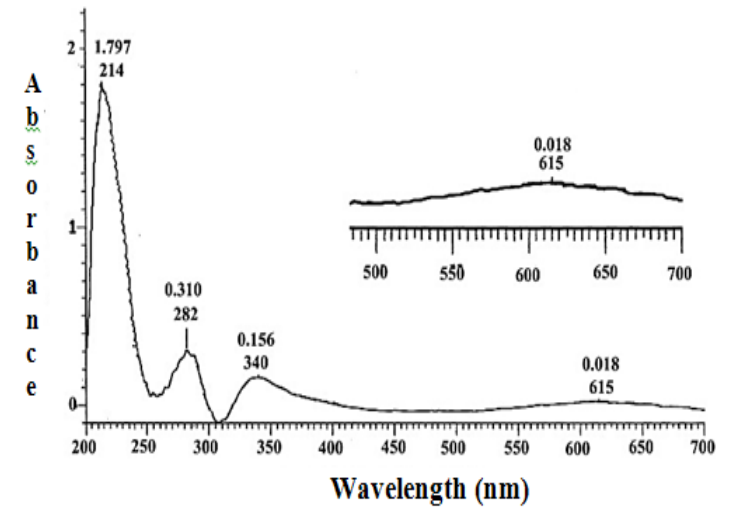

Fig. 4. Result of analysis with UV-Vis formation of quinoid base<smiles>COC(=O)c1ccc(C2(O)c3ccccc3C(=O)C2(c2ccc(O)cc2)c2ccc(C(=O)OC)cc2)cc1</smiles>

Fig. 5. Changes in phenolphthalein structure and color (16)

Paper $\mathrm{pH}$ from rosella flowers have advantages compare to wora wori flowers. $\mathrm{pH}$ Paper $\mathrm{pH}$ from rosella flowers have clearer color change and longer storage time than paper $\mathrm{pH}$ from wora wori flowers.

\section{CONCLUSION}

The rosella flowers contain anthocyanins sianidin-3-glucoside which acts as an indicator, The color of compounds turn to be red in acid solution and blue in base solution. The indicator paper is an alternative to litmus that is made from rosella flowers in which they can change color to be red in acid solutions and blue in base solutions. The color change is the same as comparative indicator of red and blue litmus.

\section{ACKNOWLEDGEMENT}

The author thanks to the Head of the Organic Chemistry Laboratory of University of Gadjah 
Mada, which has provided facilities for analysis using UV-Vis, FTIR, ${ }^{1}$ HMNR the Head of Herbarium Laboratory of Tadulako University Palu, which has helped to identify a rosella plant as a research samples.

\section{REFERENCES}

1. Nuryanti, S., Matsjeh,S., Anwar, C., dan Raharjo, T, J., J. Agritech., 2010, 30(3), 178-183.

2. Burungale, S. H. and Mali, A. V., 2014, J. of Chemical and pharmaceutical Research., 2014, 6(5), 901-903.

3. Okoduwa, S. I. R., Lovina O. M., Matthew E. A. and Ameh A. A, J. Biochemistry Research International., 2015, 2015, 381721, 1-6, http:// dx.doi.org/10.1155/2015/381721

4. Nuryanti, S., in A.Price (chief ed.), Paper Indicator of Wora-wari Flowers (Hibiscus rosa-sinensis L.), 3 th ICRIEMS (International Conference on Reseach, Implementation, and Education of Mathematics and science)., 2016, 95-98.

5. Abbas, S.K., J. of Innovations in Pharmaceuticals and Biological Sciences, 2014, 1(2), 72-76,

6. Pimpodkar, N.V., Surve, N.V., Bhise, S. H., J. of Current Pharma Research., 2014, 4(2), 124-127.

7. Nuryanti, S., Matsjeh, S., Anwar, C., Raharjo, T,J., and Hamzah, B., Eur. J. Chem., 2013, 4 (1), $20-24$.

8. Nuryanti, S., Matsjeh, S., Anwar, C., and Raharjo, T. J., Indonesian Journal of Chemistry., 2012, 12(2), 167-171.

9. Adje, F., Lozano, Y.F., Meudec, E., Lozano, P.,
Adima, A., Agbon'zi, G. and Gaydou, E.M., 2008, Molecules., 2008, 13, 1238-1245.

10. Anderson, Q.M., Fecent, T., Torskangerpoll, K., Forcen, A. and Hauge, U., Phytochem., 2004, 65, 405-410.

11. Silverstein, R.M., Bassler, G.C. and Morrill, T.C., Spectrometric Identification of Organic Structure Compounds, $5^{\text {th }}$ Edition, John Wiley \& Sons, Inc., Singapore., 1991, 117-118.

12. Mabry, TJ, Markham, KR and Thomas, MB, The Systematic Identification of Flavonoids, Springer Verlag, New York., 1970, 135-158.

13. Zhang, Y., Seeram, N.P., Lee, R., Feng, L. And Heber, D., 2008, J. Agric, Food Chem., 2008, 56, 670-675.

14. Laleh, G.H., Frydoonfar, R., Heldary, R., Jamee and Zare. S., J. Nutr., 2006, 5(1) 90-92.

15. Ologundudu, A., Ologundudu, O.A., Ololade, I.A. and Obi, F.O., J. Afr. Biochem., Research., 2009, 4, 140-144.

16. Supratman, U., Elucidation of Organic Compound Structure: Spectroscopy Method for Determination of Organic Compound Structure, Widya Padjajaran, Bandung., 2010, 20. 